\title{
Long-term comparison of thoracic endovascular aortic repair (TEVAR) to open surgery for the treatment of thoracic aortic aneurysms
}

Nimesh D. Desai, MD, PhD, Kristen Burtch, BS, William Moser, MS, Pat Moeller, BS, Wilson Y. Szeto, MD, Alberto Pochettino, MD, Edward Y. Woo, MD, Ronald M. Fairman, MD, and Joseph E. Bavaria, MD

Objective: Thoracic endovascular aortic repair (TEVAR) has become a widely established treatment for a variety of thoracic aortic pathologic diseases despite limited long-term data to support its use. We compared the long-term outcomes of TEVAR with the 3 commercially available stents grafts for thoracic aortic aneurysms to results in control subjects undergoing open surgery.

Methods: Demographic, clinical radiographic parameters were collected prospectively on patients enrolled in trials assessing the Gore TAG (55), Medtronic Talent (36) and Cook TX2 (15) devices. Outcomes were compared with 45 contemporaneous open controls. Detailed clinical and radiographic information was available for analysis. Standard univariate, survival, and regression methods were used.

Results: During the study period (1995-2007) 106 patients were enrolled in TEVAR trials and there were 45 open controls. TEVAR patients were older and had significantly more comorbidities including diabetes and renal failure. TEVAR patients had $2.3 \pm 1.3$ devices implanted. Mortality $(2.6 \%$ TEVAR, $6.7 \%$ open; $P=.1)$, paralysis/paraparesis (3.9\% TEVAR, $7.1 \%$ open; $P=.2)$, and prolonged intubation more than 24 hours $(9 \%$ TEVAR, $24 \%$ open; $P=.02$ ) tended to be more common in the open controls. Overall survival at 10 years was similar between groups ( $\log \operatorname{rank} P=.5$ ). Multivariate predictors of late mortality included age, chronic obstructive pulmonary disease, diabetes, and chronic renal failure. Use of TEVAR versus open surgery did not influence mortality (hazard ratio, 0.9 95\% confidence interval, 0.4-1.6). Over 5 years of radiographic follow-up in the TEVAR group, mean aortic diameter decreased from 61 to $55 \mathrm{~mm}$. Freedom from reintervention on the treated segment was $85 \%$ in TEVAR patients at 10 years.

Conclusions: TEVAR is a safe and effective procedure to treat thoracic aortic aneurysms with improved perioperative and similar long-term results as open thoracic aortic repair. TEVAR-treated aneurysm diameters initially decrease and then stabilize over time. (J Thorac Cardiovasc Surg 2012;144:604-11)

Earn CME credits at

http://cme.ctsnetjournals.org

Thoracic endovascular aortic repair (TEVAR) has been proposed to be a less invasive treatment for treatment of thoracic aortic aneurysms. Early clinical results with thoracic

\footnotetext{
From the Departments of Cardiovascular Surgery and Vascular Surgery, Hospital of the University of Pennsylvania, Philadelphia, Pa.

Disclosures: Authors have nothing to disclose with regard to commercial support.

Read at the 91st Annual Meeting of The American Association for Thoracic Surgery, Philadelphia, Pennsylvania, May 7-11, 2011.

Received for publication May 17, 2011; revisions received April 29, 2012; accepted for publication May 16, 2012.

Address for reprints: Nimesh D. Desai, MD, PhD, Division of Cardiovascular Surgery, Hospital of the University of Pennsylvania, 3400 Spruce St, 6th Floor Silverstein Pavilion, Philadelphia, PA 19096 (E-mail: nimesh.desai@uphs.upenn.edu). 0022-5223/\$36.00

Copyright $\Subset 2012$ Published by Elsevier Inc. on behalf of The American Association for Thoracic Surgery

doi:10.1016/j.jtcvs.2012.05.049
}

aortic stent grafts have shown significantly improved early quality of life versus open surgery and have generally shown a trend toward better perioperative survival and freedom from major complications. ${ }^{1-4}$ The original Food and Drug Administration Investigational Device Exemption (FDA IDE) studies that led to approval of the currently available devices, including the Gore TAG (W. L. Gore \& Associates, Inc, Flagstaff, Ariz), Medtronic Talent (Medtronic, Inc, Minneapolis, Minn), and Cook Zenith TX2 stent grafts (Cook Endovascular, Bloomington, Ind), specifically looked at patients with favorable anatomy in descending thoracic aortic aneurysms. ${ }^{5-7}$ The early results in these trials were highly favorable toward stent grafts. However, little is known about the long-term fate of thoracic aneurysms treated by TEVAR. The purpose of this investigation is to determine the long-term survival and freedom from aortic complications in patients enrolled in 5 FDA IDE studies of TEVAR grafts from a single center and compare them with a group of open control patients with similar anatomic features. 


\section{Abbreviations and Acronyms \\ FDA $=$ Food and Drug Administration \\ IDE = Investigational Device Exemption \\ TEVAR $=$ thoracic endovascular aortic repair}

\section{METHODS \\ Patients}

All patients enrolled at the Hospital of the University of Pennsylvania in the Gore 99-01 (14 patients), Gore 03-03 (10 patients), Gore 04-02 (16 patients), Medtronic Talent (33 patients), Cook TX2 (14 patients), and Gore 05-02 (13 patients) clinical trials were included in the study. A comparator group of 45 open cases with descending thoracic aortic aneurysms in a fairly contemporary period was identified from a total of 204 open thoracic/thoracoabdominal aortic cases. The patients selected in the open control group had anatomy that was amenable to TEVAR with a proximal and distal neck of at least $2 \mathrm{~cm}$ with maximal neck diameters that could be treated by available TEVAR devices and did not have excessive angulation or tapering. Some of the controls (6/45) were not amenable to crossclamping proximally owing to friability or calcification and the operations were performed under circulatory arrest conditions with an open anastomosis. Reverse hemiarch type anastomoses were excluded. Only aneurysmal disease was included.

\section{Surgical Techniques}

TEVAR at the Hospital of the University of Pennsylvania is performed by a multidisciplinary team including cardiovascular surgery, vascular surgery, cardiovascular anesthesia, neurology, and diagnostic radiology. The majority of cases were performed in a dedicated hybrid operating room able to accommodate with a fixed high-quality floor-mounted image intensifier, transesophageal echocardiography equipment, intravascular ultrasound, neuromonitoring equipment and a cardiopulmonary bypass pump if necessary, and multiple movable viewing screens that can display angiography, hemodynamics, transesophageal echocardiography, and intravascular ultrasound simultaneously. ${ }^{8}$

A fairly liberal approach to retroperitoneal access is used in cases of marginal femoral access, which generally occurred in vessels that were small, heavily circumferentially calcified, or extremely tortuous. In instances of planned left subclavian artery coverage, prophylactic left common carotid artery-left subclavian artery bypass is performed perioperatively. Coiling of the left subclavian artery from the ipsilateral brachial artery is routine in cases of left common carotid artery-left subclavian artery bypass at the time of stent insertion. ${ }^{9}$

Open cases were done generally with left atrial-left femoral artery partial bypass (2-3 L flow) maintaining proximal mean perfusion pressures of 90 to $100 \mathrm{~mm} \mathrm{Hg}$ and distal mean pressures of 70 to $80 \mathrm{~mm} \mathrm{Hg}$. Sequential clamping was performed to minimize ischemic times. Large viable intercostals arteries were preserved either by beveling the distal anastomosis or by selective reimplantation. Circulatory arrest cases were performed using electroencephalography and somatosensory evoked potential monitoring. In circulatory arrest cases, bypass was initiated via the femoral artery and vein and a left ventricular vent was placed via the left inferior pulmonary vein or apex. Patients were cooled to electroencephalographic silence or $18^{\circ} \mathrm{C}$, and total body retrograde perfusion was performed to keep the vasculature deaired. ${ }^{10}$

\section{Neuroprotective Strategies}

Use of somatosensory evoked potential monitoring was not standardized in this population but evolved into a routine with increasing experience. Preoperative spinal drains were used in all patients who were considered at high risk for spinal ischemia including those with previous abdominal aortic aneurysm repair, descending thoracic aortic surgery, or planned complete aortic coverage from the left subclavian to the celiac axis. Descending thoracic aortic coverage was classified according to the method proposed by Safi ${ }^{11}$ : type A, left subclavian artery to midthoracic aorta (T6); type B, midthoracic aorta (T6) to celiac axis; or type C, left subclavian to celiac axis. The protocol for management of spinal cord ischemia in the postoperative period included spinal drainage to cerebrospinal fluid pressure below $10 \mathrm{~cm} \mathrm{H}_{2} \mathrm{O}$ and aggressive blood pressure augmentation with mean arterial pressures over $90 \mathrm{~mm} \mathrm{Hg} .{ }^{12}$

\section{Data, Statistical Methods, and Follow-up}

Perioperative data were abstracted from the Penn Thoracic Aortic Database, a prospectively maintained database containing detailed demographic, operative, and device information. Long-term follow-up was performed on an annual basis for at least 5 years in the TEVAR patients as part of the various trial protocols with clinical follow-up and computed tomographic scans. Telephone clinical assessments and outpatient clinic records were also abstracted for open control and TEVAR patients. Follow-up was $95 \%$ complete at a minimum of 3 years. Median followup interval was 66 months (interquartile range, 32 to 79 months) in TEVAR and 91 months (interquartile range, 29 to 123 months) for open control patients. Late aortic reinterventions were characterized according to whether they involved the previously treated segment of aorta including proximal and distal landing zones or an unrelated segment such as the infrarenal aorta or a de novo ascending aneurysm.

Early outcomes were compared using standard univariate statistics including the Student $t$ test for continuous data and Fisher's exact test for categorical data. Multivariate analyses for predictors of operative mortality were determined using logistic regression. All variables deemed clinically relevant were maintained in the model and no automated selection procedures were used. Late survivals were analyzed using the Kaplan-Meier survival technique, and multivariate predictors of late survival were determined using Cox proportional hazards modeling. Late survival data were determined using a linkage to the national Social Security Death Index. The study protocol was approved by the local institutional review board.

\section{RESULTS}

Between 1999 and 2007, we enrolled 106 patients in the 5 FDA IDE studies. Open controls were chosen on the basis of anatomic characteristics in the period between 1994 and 2004 (Figure 1). TEVAR patients were significantly older (74.3 \pm 91 years vs $69.5 \pm 11.1$ years; $P=.006$ ) and had a higher proportion of diabetes and renal failure than open control patients. Demographic information is presented in Table 1.

Open control procedures were predominantly performed on left atrial-femoral artery bypass $(39 / 45,86 \%)$ with the remaining $6(14 \%)$ being performed on circulatory arrest. Mean bypass time was $84 \pm 41$ minutes and crossclamp time was $55 \pm 20$ minutes. In circulatory arrest cases, mean arrest time was $36 \pm 8.5$ minutes (Table 2).

Among open control patients, 16 (35.6\%) underwent Safi type A aortic replacement, $2(4.4 \%)$ underwent type B replacement, and $27(60 \%)$ underwent type $C$ replacement. Preoperative spinal drains were placed in $36 / 45(80 \%)$ of open cases. Among TEVAR patients, 38 (36\%) underwent type A aortic coverage, 28 (26\%) underwent type B coverage, and 40 (38\%) underwent type $\mathrm{C}$ coverage. Preoperative spinal drains were placed in $49(47 \%)$ of 106 TEVAR cases. 


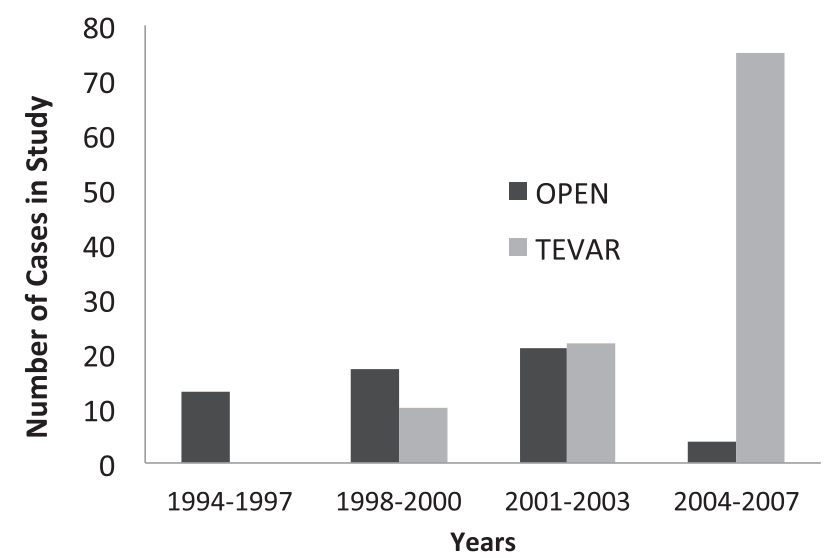

FIGURE 1. Distribution of open and thoracic endovascular aortic repair (TEVAR) cases in the study over time.

Among TEVAR patients, 18 of 106, all in the type A or C coverage group, underwent preoperative carotid subclavian bypass with anticipated coverage of the origin of the left subclavian artery. There were 4 cases of subclavian coverage without previous bypass. The mean number of stents implanted were $1.9 \pm 0.9$ for the Gore TAG, $3.2 \pm 1.5$ for the Medtronic Talent, and $1.8 \pm 0.8$ for Cook Zenith TX2. There were $18(16.9 \%)$ access complications including 4 managed with an iliac artery stent, 8 managed with an open repair or bypass of the iliac artery, and 8 managed with local femoral artery repair, thrombectomy, or endarterectomy.

Overall, 30-day mortality was $2.8 \%$ for TEVAR and $6.7 \%$ for open control patients $(P=.4)$, and in-hospital mortality was $2.8 \%$ for TEVAR and $8.9 \%$ for open control patients $(P=.1)$. Paraparesis or permanent paralysis occurred in $3.8 \%$ of TEVAR and $6.7 \%$ of open patients $(P=.4)$, whereas permanent paralysis occurred in $1.9 \%$ of TEVAR and $4.4 \%$ of open patients, respectively

TABLE 1. Preoperative characteristics

\begin{tabular}{lccc}
\hline \multicolumn{1}{c}{ Feature } & $\begin{array}{c}\text { TEVAR, } \\
\text { N (\%) }\end{array}$ & $\begin{array}{c}\text { Open controls, } \\
\text { N (\%) }\end{array}$ & $\boldsymbol{P}$ value \\
\hline $\mathrm{N}$ & 106 & 45 & \\
Age & $74.3 \pm 9.1$ & $69.5 \pm 11.1$ & .006 \\
Female & $46(43 \%)$ & $27(60 \%)$ & .07 \\
Smoking & $82(77 \%)$ & $40(89 \%)$ & .1 \\
COPD & $41(39 \%)$ & $24(53 \%)$ & .1 \\
Prior CVA & $9(9 \%)$ & $7(16 \%)$ & .2 \\
Hypertension & $94(88 \%)$ & $40(89 \%)$ & .7 \\
Previous MI & $20(19 \%)$ & $9(20 \%)$ & .4 \\
Previous CABG & $16(15 \%)$ & $7(16 \%)$ & .9 \\
Diabetes & $22(21 \%)$ & $3(6.7 \%)$ & .03 \\
Renal failure & $11(10 \%)$ & $1(2.2 \%)$ & .04 \\
Acute presentation & $9(9 \%)$ & $7(16 \%)$ & .4 \\
\hline
\end{tabular}

TEVAR, Thoracic endovascular aortic repair; $C O P D$, chronic obstructive pulmonary disease; $C V A$, cerebrovascular accident; $M I$, myocardial infarction; $C A B G$, coronary artery bypass grafting.
TABLE 2. Operative characteristics

\begin{tabular}{ll}
\hline \multicolumn{1}{c}{ Operative data } & \\
\hline TEVAR $(\mathbf{n}=\mathbf{1 0 6})$ & \\
No. of devices implanted & $2.3 \pm 1.3$ \\
- Gore TAG $(\mathrm{n}=55)$ & $1.9 \pm 0.9$ \\
- Medtronic Talent $(\mathrm{n}=36)$ & $3.2 \pm 1.5$ \\
- Cook TX2 $(\mathrm{n}=15)$ & $1.8 \pm 0.8$ \\
Preop left carotid-subclavian bypass & $18(16.9 \%)$ \\
Access complication & \\
- Iliofemoral dissection/tear & $18(16.9 \%)$ \\
- Stent & $4(3.7 \%)$ \\
- Open repair/bypass & $8(7.5 \%)$ \\
- Local femoral repair/thrombectomy/ & $8(7.5 \%)$ \\
$\quad$ endarterectomy & \\
Open cases (n = 45) & \\
Perfusion & $39(86 \%)$ \\
Partial left heart bypass & $6(14 \%)$ \\
Full bypass with circulatory arrest & $55 \pm 20$ \\
Crossclamp time (min) & $84 \pm 41$ \\
Cardiopulmonary bypass time (min) & $36 \pm 8.5$ \\
\hline Circulatory arrest time (min)
\end{tabular}

TEVAR, Thoracic endovascular aortic repair.

$(P=.6)$. Stroke or transient ischemic attack occurred in $4.7 \%$ of TEVAR patients and $6.7 \%$ of open patients $(P=.6)$. Permanent stroke occurred in $1.9 \%$ of TEVAR patients and $2.2 \%$ of open patients $(P=.7)$. Prolonged intubation for more than 24 hours occurred in $10 \%$ of TEVAR and $22 \%$ of open patients $(P=.06)$. Overall, $10 \%$ of TEVAR patients and $31 \%$ of open patients experienced death, permanent stroke, paralysis, or prolonged assisted ventilation $(P=.003)$. There were no instances of arm ischemia requiring treatment and all 4 patients with unplanned left subclavian artery coverage had no postoperative neurologic sequelae (Table 3).

Overall survival at 8 to 10 years was similar between groups ( $\log$ rank $P=.5$ ) (Figure 2). Multivariate predictors of late mortality included age, chronic obstructive pulmonary disease, and chronic renal failure (Table 4). Use of TEVAR versus open surgery did not influence late mortality in a risk-adjusted

TABLE 3. Perioperative results

\begin{tabular}{lrcc}
\hline \multicolumn{1}{c}{$\begin{array}{c}\text { Post-operative } \\
\text { characteristics }\end{array}$} & $\begin{array}{c}\text { TEVAR } \\
(\mathbf{N}=\mathbf{1 0 6})\end{array}$ & $\begin{array}{c}\text { Open controls } \\
(\mathbf{N}=\mathbf{4 5})\end{array}$ & $\begin{array}{c}\boldsymbol{P} \\
\text { value }\end{array}$ \\
\hline Thirty-day mortality & $3(2.8 \%)$ & $3(6.7 \%)$ & .4 \\
Hospital mortality & $3(2.8 \%)$ & $4(8.9 \%)$ & .1 \\
Paralysis/paraparesis & $4(3.8 \%)$ & $3(6.7 \%)$ & .4 \\
Permanent paralysis & $2(1.9 \%)$ & $2(4.4 \%)$ & .6 \\
Stroke/transient ischemic & $5(4.7 \%)$ & $3(6.7 \%)$ & .6 \\
$\quad$ & & & \\
$\quad$ attack & $2(1.9 \%)$ & $1(2.2 \%)$ & .7 \\
Permanent stroke & $10(9.6 \%)$ & $10(22 \%)$ & .06 \\
Prolonged intubation $(>24 \mathrm{~h})$ & $11(10 \%)$ & $14(31 \%)$ & .003 \\
Composite & & & \\
(death, paralysis, permanent & & & \\
\multicolumn{1}{c}{ stroke, intubation $>24 \mathrm{~h})$} & &
\end{tabular}




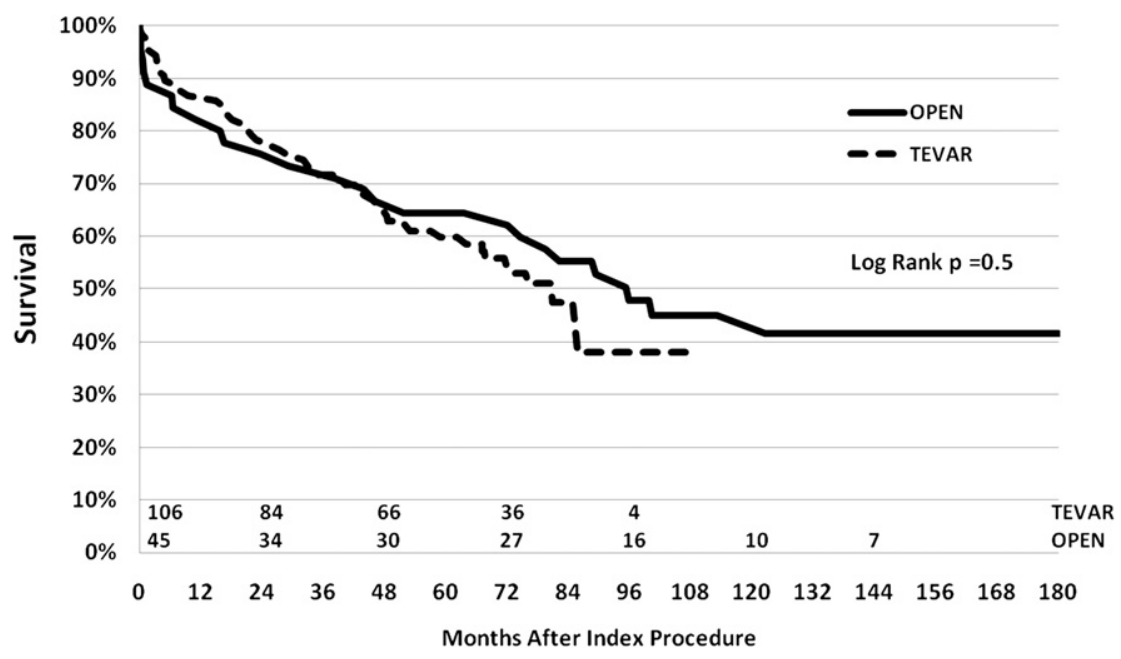

FIGURE 2. Long-term survival. TEVAR, Thoracic endovascular aortic repair.

Cox proportional hazards regression model (hazard ratio, .9; $95 \%$ confidence interval, $0.8-1.6$ ). Women had better survival than men in long-term follow-up (hazard ratio, $0.6 ; 95 \%$ confidence interval, 0.5-0.9), but this effect was only seen in the open group (gender - group interaction; $P=.01$ ).

There were 19 aortic reinterventions in the treated segments in the TEVAR group in 14 patients. One retrograde type A aortic dissection was found in imaging 3 months after index TEVAR, and 1 retrograde type A dissection was found after a reintervention with a proximal extension. Both retrograde type A dissections were treated with open arch repair with 1 perioperative mortality. Three other open reinterventions were needed for failure to achieve adequate seal in the treated segment (type I endoleak). There were 14 endovascular reinterventions on the treated segment including 11 for type I endoleaks and 3 type 3 endoleaks. Overall freedom from reintervention on the treated segment was $85.7 \% \pm 3.6 \%$ in TEVAR patients at 8 years (Figure 3) There were no treated segment reinterventions in the open group (log rank $P=.02$ for TEVAR vs open comparison). There

TABLE 4. Predictors of late mortality (Cox proportional hazards regression)

\begin{tabular}{lcc}
\hline \multicolumn{1}{c}{ Characteristic } & Hazard ratio & $\mathbf{9 5 \%} \mathbf{C I}$ \\
\hline Age & 1.1 & $1.0-1.2$ \\
Female* & 0.6 & $0.5-0.9$ \\
Hypertension & 1.6 & $0.7-3.5$ \\
Diabetes & 1.1 & $0.7-2.3$ \\
CAD & 1.3 & $0.8-1.8$ \\
Cerebrovascular disease & 1.2 & $0.7-1.2$ \\
COPD & 1.9 & $1.1-2.7$ \\
Chronic renal failure & 1.7 & $1.1-2.6$ \\
TEVAR vs open & 0.9 & $0.8-1.6$ \\
\hline
\end{tabular}

$C I$, Confidence interval; $C A D$, coronary artery disease; $C O P D$, chronic obstructive pulmonary disease; TEVAR, thoracic endovascular aortic repair. *Gender group interaction, $P=.01$. were 9 late unrelated aortic interventions in the TEVAR group including 7 infrarenal aorta or iliac artery and 2 ascending aorta. There was 1 infrarenal and 1 ascending aortic intervention in the open group. Over 5 years of radiographic follow-up in the TEVAR group, mean aortic diameter decreased $5.7 \pm 10.3 \mathrm{~mm}$ from $61.0 \pm 9.9$ $\mathrm{mm}$ to $55.3 \pm 13.4 \mathrm{~mm}(P=.01)$ (Figure 4$)$. Over the 5 -year period, $60.3 \%$ of patients had regression of aortic diameters, $7.5 \%$ had an increase of greater than $5 \mathrm{~mm}$, and the remainder had no change.

\section{DISCUSSION}

Traditional open repair of the thoracic aorta is traditionally associated with significant permanent neurologic morbidity and mortality. In recent series from high-volume centers of excellence, mortality and neurologic morbidity rates range from $5.4 \%$ to $7.2 \%$ for mortality, $2.1 \%$ to $6.2 \%$ for permanent stroke, $5.7 \%$ for permanent paraparesis, and $0.8 \%$ to $2.3 \%$ for permanent paralysis, respectively. ${ }^{13,14}$ In the multicenter open control groups for the Gore TAG, Medtronic Talent, and Cook Zenith TX2 stent grafts, mortality and neurologic morbidity rates range from $5.7 \%$ to $11.7 \%$ for mortality, $4.3 \%$ to $8.6 \%$ for permanent stroke, $5.7 \%$ for permanent paraparesis, and $3.4 \%$ to $8.5 \%$ for permanent paralysis, respectively. ${ }^{5-7}$ In reference to these findings, mortality and morbidity in our open control group were comparable at $6.7 \%$ mortality, $2.2 \%$ stroke, $2.2 \%$ permanent paraperesis, and $4.4 \%$ permanent paralysis.

Similarly, the perioperative results for the 3 stent graft trials in the TEVAR arms showed $1.9 \%$ to $2.1 \%$ for mortality, $2.4 \%$ to $4 \%$ for stroke, $4.4 \%$ to $7.2 \%$ for permanent paraparesis, and $1.3 \%$ to $3 \%$ for permanent paralysis, respectively. ${ }^{5-7}$ Again, our results were similar with $2.8 \%$ mortality, $1.9 \%$ for stroke, $1.9 \%$ for permanent paraparesis, and $1.9 \%$ for permanent paralysis, respectively. ${ }^{5-7}$ 


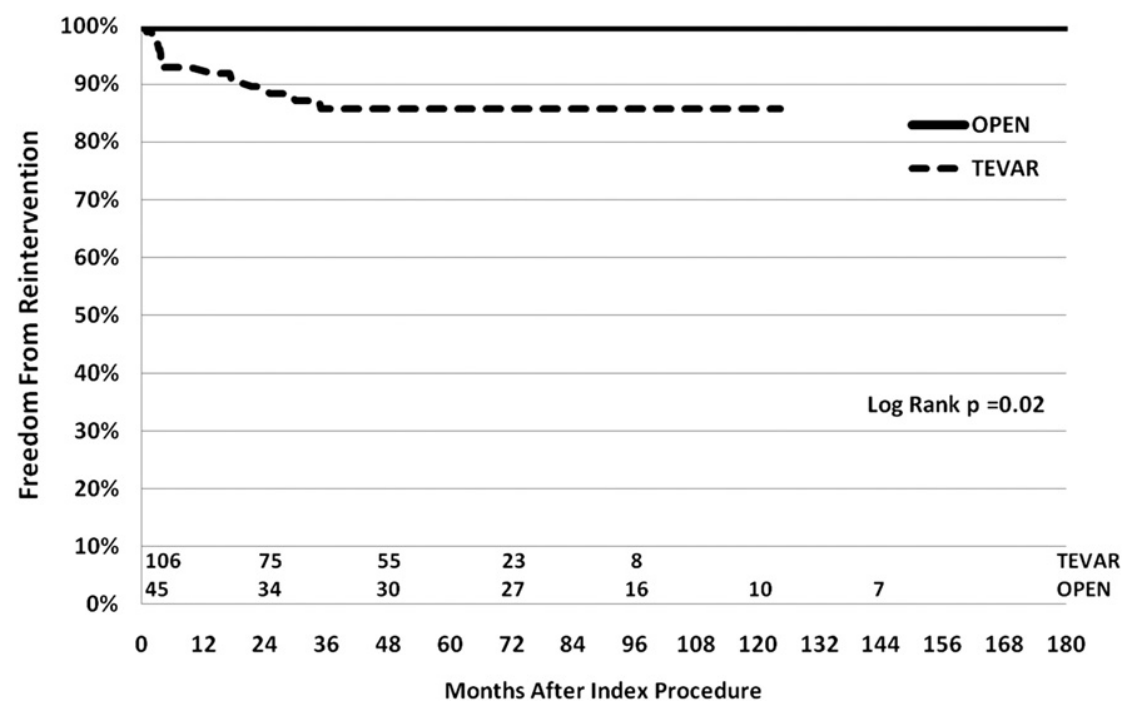

FIGURE 3. Freedom from treated aortic segment reintervention. TEVAR, Thoracic endovascular aortic repair.

Although the use of TEVAR has proliferated rapidly, longterm data regarding the efficacy of this procedure to prevent premature death are absent. Extrapolating on data from abdominal stent-grafting studies in which there was no long-term survival benefit for intervention versus medical therapy ${ }^{15}$ some authors have proposed that TEVAR does not change the natural history of the disease, and, although less invasive, may be inferior to open therapies. ${ }^{16}$ The key finding of this study is that over a 5- to 10-year horizon, TEVAR patients clearly had more reinterventions than open control patients but had identical all-cause mortality. Given the dramatically older age of the TEVAR patients, we had expected a higher unadjusted mortality in the TEVAR group and our results indicate that surgeons can safely apply this strategy. This finding also demonstrates the importance of repeat surveillance imaging in TEVAR patients and a rigorous

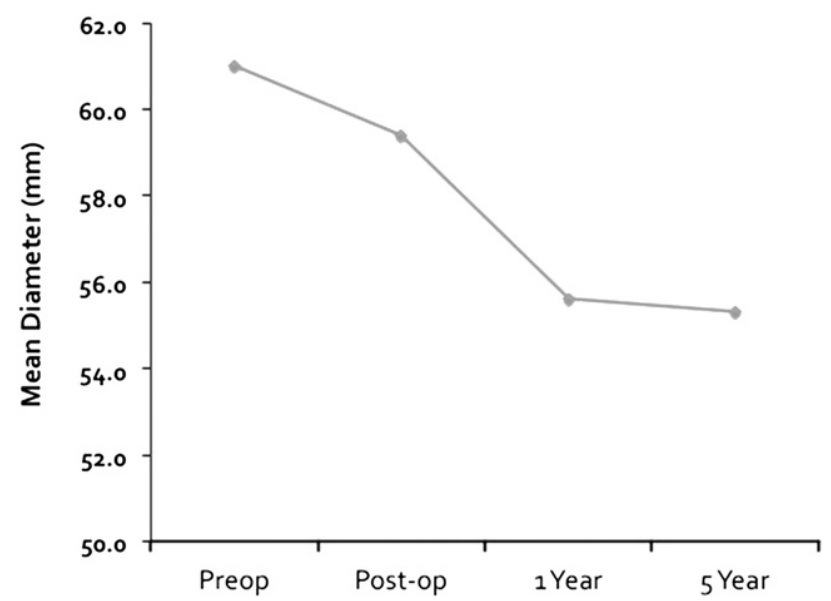

FIGURE 4. Change in aortic dimensions over time in thoracic endovascular aortic repair (TEVAR) patients. approach to reintervention in cases in which there is progression. The overall decline in aneurysm size appeared to be durable, although we only had detailed imaging information at 5 years in a small group of patients.

In this series, many of the open patients between 2001 and 2003 were initially evaluated to be enrolled in the Gore TAG 99-02 trial for TEVAR, but this trial was halted to redesign the Gore TAG stent graft owing to spine fractures. As a result, these patients no longer had access to an endovascular device and were treated with open surgery. In our series, we had 1 incidence of stent spine fracture in a well-sealed aneurysm that did not require any further reintervention.

In the overall series, $9.4 \%$ of patients had a significant access issue requiring more than a local femoral artery repair and a further $7.5 \%$ required simple local femoral endarterectomy and/or thrombectomy. Access complications were fairly frequent in the earliest patients in the series and with increased experience and optimal device selection have become uncommon. Our analysis of a larger group of TEVAR patients showed a distinct diminishment in access complications over time.

Since the first implants of 'home-made' grafts constructed on the back table, TEVAR devices have become smaller, more flexible, have improved device conformability, less porosity, and more sizing options. ${ }^{17-19}$ Many of the cases in this series were our institutional first experiences with TEVAR grafts, and over time our experience has guided our practice toward improved clinical case planning and outcomes. Evolution of the multidisciplinary TEVAR team to include cardiac and vascular surgeons, cardiovascular anesthesia, diagnostic radiology, and neurologists has enabled application of this technology to sicker patients while maintaining outcomes. ${ }^{20}$ 


\section{Study Limitations}

The current study, while controlled using anatomic inclusion criteria, is not randomized and therefore subject to selection, measurement, and attribution biases. Small sample sizes, although similar to those of the multicenter pivotal FDA studies for these stent grafts, further limit the overall generalizability of the results and our ability to perform complex risk adjustment. Further, this study is from a single center highly experienced in this procedure, and multicenter data would be more generalizable. Our use of all-cause mortality instead of aorta-related mortality was due to the longitudinal retrospective nature of the study. As such, we did not have detailed specific information about the exact cause of death in some patients to delineate aortic deaths from other causes. We propose that the all-cause mortality outcome we used in this study is the most stringent and appropriate for aortic patients inasmuch as sudden death is a frequent end point from aortic rupture and is not subject to attribution biases.

\section{SUMMARY}

Among the patients in this study, TEVAR was both safe and effective in the short and long term to treat thoracic aortic aneurysms and offered similar survival to open therapies. TEVAR patients did require repeat interventions more frequently, although the vast majority of these are performed by an endovascular approach. Aneurysm dimensions appear to decrease maximally in the first year and remain stable from that point onward. Further follow-up of these patients is planned and larger multicentric studies will provide further confirmation of these findings.

\section{References}

1. Gopaldas RR, Huh J, Dao TK, LeMaire SA, Chu D, Bakaeen FG, et al. Superior nationwide outcomes of endovascular versus open repair for isolated descending thoracic aortic aneurysm in 11,669 patients. J Thorac Cardiovasc Surg. 2010; 140:1001-10

2. Andrassy J, Weidenhagen R, Meimarakis G, Rentsch M, Jauch KW, Kopp R. Endovascular versus open treatment of degenerative aneurysms of the descending thoracic aorta: a single center experience. Vascular. 2011;19:8-14.

3. Orandi BJ, Dimick JB, Deeb GM, Patel HJ, Upchurch GR Jr. A population-based analysis of endovascular versus open thoracic aortic aneurysm repair. $J$ Vasc Surg. 2009;49:1112-6.

4. Abraha I, Romagnoli C, Montedori A, Cirocchi R. Thoracic stent graft versus surgery for thoracic aneurysm. Cochrane Database Syst Rev. 2009 Jan 21;1: CD006796.

5. Bavaria JE, Appoo JJ, Makaroun MS, Verter J, Yu ZF, Mitchell RS. Gore TAG Investigators. Endovascular stent grafting versus open surgical repair of descending thoracic aortic aneurysms in low-risk patients: a multicenter comparative trial. J Thorac Cardiovasc Surg. 2007;133:369-77.

6. Fairman RM, Criado F, Farber M, Kwolek C, Mehta M, White R. VALOR Investigators. Pivotal results of the Medtronic Vascular Talent Thoracic Stent Graft System: the VALOR trial. J Vasc Surg. 2008;48:546-54.

7. Matsumura JS, Cambria RP, Dake MD, Moore RD, Svensson LG, Snyder S. TX2 Clinical Trial Investigators. International controlled clinical trial of thoracic endovascular aneurysm repair with the Zenith TX2 endovascular graft: 1-year results. J Vasc Surg. 2008;47:247-57

8. Brinkman WT, Szeto WY, Bavaria JE. Stent graft treatment for transverse arch and descending thoracic aorta aneurysms. Curr Opin Cardiol. 2007;22:510-6.
9. Woo EY, Carpenter JP, Jackson BM, Pochettino A, Bavaria JE, Szeto WY, et al. Left subclavian artery coverage during thoracic endovascular aortic repair: a single-center experience. J Vasc Surg. 2008;48:555-60.

10. Augoustides JG, Pochettino A, Ochroch EA, Cowie D, McGarvey ML, Weiner J, et al. Clinical predictors for prolonged intensive care unit stay in adults undergoing thoracic aortic surgery requiring deep hypothermic circulatory arrest. J Cardiothorac Vasc Anesth. 2006;20:8-13.

11. Safi HJ, Miller CC III, Iliopoulos DC, Letsou GV, Baldwin JC. Staged repair of extensive aortic aneurysm: improved neurologic outcome. Ann Surg. 1997;226: 599-605.

12. Cheung AT, Pochettino A, McGarvey ML, Appoo JJ, Fairman RM, Carpenter JP, et al. Strategies to manage paraplegia risk after endovascular stent repair of descending thoracic aortic aneurysms. Ann Thorac Surg. 2005;80:1280-8.

13. Wong DR, Parenti JL, Green SY, Chowdhary V, Liao JM, Zarda S, et al. Open repair of thoracoabdominal aortic aneurysm in the modern surgical era: contemporary outcomes in 509 patients. J Am Coll Surg. 2011;212:569-79.

14. Estrera AL, Miller CC 3rd, Chen EP, Meada R, Torres RH, Porat EE, et al. Descending thoracic aortic aneurysm repair: 12-year experience using distal aortic perfusion and cerebrospinal fluid drainage. Ann Thorac Surg. 2005;80:1290-6.

15. Malas MB, Freischlag JA. Interpretation of the results of OVER in the context of EVAR trial, DREAM, and the EUROSTAR registry. Semin Vasc Surg. 2010;23: 165-9.

16. Elefteriades JA, Farkas EA. Thoracic aortic aneurysm clinically pertinent controversies and uncertainties. J Am Coll Cardiol. 2010;55:841-57.

17. Dake MD, Miller DC, Semba CP, Mitchell RS, Walker PJ, Liddell RP. Transluminal placement of endovascular stent-grafts for the treatment of descending thoracic aortic aneurysms. $N$ Engl J Med. 1994;331:1729-34.

18. Milner R, Bavaria JE, Baum RA, Carpenter JP, Velazquez OC, Brinster D, et al. Thoracic aortic stent grafts. Semin Roentgenol. 2001;36:340-50.

19. Gawenda M, Brunkwall J. Comparison of CE approved TEVAR devices. J Cardiovasc Surg (Torino). 2010;51:157-68.

20. Czerny M, Funovics M, Ehrlich M, Hoebartner M, Sodeck G, Dumfarth J, et al Risk factors of mortality in different age groups after thoracic endovascular aortic repair. Ann Thorac Surg. 2010;90:534-8.

\section{Discussion}

Dr John S. Ikonomidis (Charleston, SC). I have no relationships to disclose that are relevant to this discussion. Nimesh, I enjoyed your presentation very much. We clearly need more data with regard to long-term outcomes in these patients.

I would like to raise a few issues related to your patient groups. First, with the control open group, I am a little puzzled by your choice to include 6 patients who had hypothermic circulatory arrest. Why did you choose to enter those patients into this analysis when, clearly, circulatory arrest is not used in the stent graft group, and we know from many studies that the use of circulatory arrest in aortic surgery, especially longer times, is itself a predictor of neurologic outcome and even mortality? The second part of that question is, what happens to the control group if you eliminate those 6 patients?

Dr Desai. Thank you for the question. Our inclusion was based on defined anatomic substrates. If a patient had an adequate zone 2 landing zone, he or she was considered appropriate to include in the study. Not all patients with zone 2 landing zones cannot necessarily undergo crossclamping. In this case, when the operative reports were reviewed, the reasons for not clamping the aorta in that region were aortic calcification or mobile atheroma. By comparison, the TEVAR IDE studies, particularly the VALOR trial (Vascular Talent Thoracic Stent Graft System for the Treatment of Thoracic Aortic Aneurysms) for the Talent device, $40 \%$ of the patients in that group had bare metal going into zone 2 or even zone 1. These are patients who can be treated with TEVAR, but if the operations are done open they may require circulatory arrest. They 
were absolutely not reverse hemiarches and they were not treating patients who could not be treated with TEVAR.

To answer your other question about what happens if we remove these patients from the group: We had 1 mortality in that group and 1 stroke. The numbers are too small to really parse out those kinds of details, and the overall objective of the study was to look at the long-term not short-term outcomes; however, they would make the open controls seem slightly better in the perioperative period. I believe it is more fair to go by anatomy as we did in this article, because these are people in whom we could have used a stent.

Dr Ikonomidis. While I understand that the main purpose of this study was to assess long-term outcome, nevertheless I am interested in some of the short-term information on these patients. For example, I noticed that you had 38 patients in the TEVAR group that had so-called A anatomy. From the diagram that you showed, it looks as though aneurysms in this group originate very close to the left subclavian to the point that one would presume that those patients had their left subclavian covered as part of their procedure. Is that correct?

Dr Desai. As this was so early in our experience and these were trial patients, we did not challenge into the arch with the TEVAR graft as much as we would today. Many were very isolated aneurysms in the proximal thoracic aorta and had a reasonable landing zone between the aneurysm and the takeoff of the subclavian. We may have flared into the left subclavian or put bare metal into it but not actually covered it.

There were only 4 patients who had unplanned, that is, no preoperative left carotid-subclavian bypass, coverage of the left subclavian, and we did not have any neurologic sequelae or arm ischemia in those patients.

Dr Ikonomidis. What about cerebrospinal fluid drains? I noticed that in the open group about $80 \%$ of patients got cerebrospinal fluid drains in contrast to the TEVAR group, in which $40 \%$ got drains. How did your neurologic complication rates distribute between those groups? Do you think that you could modify your results in the TEVAR group by more aggressive use of cerebrospinal fluid drains? Has your strategy changed?

Dr Desai. Our strategy has not changed. The TEVAR group had less type $\mathrm{C}$ coverage, so in general there was less aorta covered and fewer intercostals disrupted. This explains most of the difference in the rate of placement of drains. There are other factors on which I did not elaborate here, including previous ascending aortic aneurysm repair, which influence our use of drains as well. Again, we are only looking at 4 or 5 incidents of paralysis within the whole group, including both cohorts. It is impossible to parse out those details.

Our protocol is that we place a drain for type C coverage and any other previous aortic intervention in the abdominal aorta.

Dr Ikonomidis. The last issue I wanted to bring up was the iliofemoral arterial access complication rate. Almost 1 in 5 patients in the TEVAR group had some sort of iliofemoral arterial access complication. I presume all of these were not "femoral artery or iliac artery on a stick" type complications. Nevertheless, it seems to me that this rate is a bit high. Was this part of a learning curve in the way you evaluated your patients? Did you see these complications evenly distributed over the time period? Have you modified the way you assess your patients preoperatively in terms of your strategy for TEVAR as a result of this?
Dr Desai. We have definitely become more liberal with retroperitoneal access and also have more devices to choose from, some of which have smaller profiles and are more flexible. There is definitely a learning curve component. When we presented our larger series of 500 TEVARs at the Western Thoracic in 2009, we showed that the incidence of access complications between the first 250 stent grafts we did and the second had been cut in half dramatically, and they have become extremely uncommon with the preoperative planning and our approach to access in the current era. Similarly, actually, postoperative or perioperative spinal ischemia in our TEVAR patients has virtually disappeared as an entity, and it goes beyond just putting in a drain but also hemodynamic management approaches that we have adopted.

Dr D. Craig Miller (Stanford, Calif). I am looking around for Alberto Pochettino, Joe Bavaria, or Wilson Szeto, because I am not sure it is fair to ask Nimesh some pretty tough questions. I am afraid you will feel like John Ikonomidis just softening you up.

You have a problem with small numbers of patients and a relatively small number of adverse events in both groups, as you already have admitted; therefore, how can you really draw any broad inferences? You also did not take full statistical advantage of this retroelective analysis, despite matching for the patients' anatomy. Wouldn't this be a beautiful place to use propensity score analysis to neutralize for the effects of confounding independent variables? You will unbalance the numbers, but at least you are going to have a more apples-to-apples comparison. I do not think our standard level of clinical research reporting today can allow retrospective comparative observations to be presented without adjusting as much as possible for known confounders. However, the numbers are small and may not be sufficient to generate a stable propensity model. We really need a rigorous multicenter collaborative approach with larger patient numbers to answer the important questions you are asking. Admittedly, we all are guilty of cluttering the literature with our own relatively small single-center reports, but we must figure out ways to do better.

Second, I am afraid your conclusion slide should be redone. Your data do not substantiate the conclusion about less morbidity with TEVAR. The only odds ratio that was significant was the interaction for women in the open group. All of the other odds ratios crossed 1.0. How can you really conclude there is less morbidity with TEVAR?

Dr Desai. Just to answer your first question about multivariate adjustment, when we ran propensity matching, we encountered issues with data loss.

Dr Miller. There weren't enough comparable patients?

Dr Desai. There was a paucity of matched pairs. The Cox proportional hazard model that I presented provides a similar risk adjustment, although not as visually elegant or easy to understand as propensity matching. It is full multivariate risk with similar fidelity to propensity adjustment.

In terms of morbidity issues, we showed in the perioperative period that prolonged ventilation was statistically significantly more common in open patients. The other complications also tended to be higher in open patients, and in a larger sample that difference may or may not be significant. 
The issue of renal failure in the perioperative period is one that is likely to be significant in a larger series. I think you would be hard pressed to show major differences, even in a fairly large trial, in terms of mortality, spinal complications, or stroke with contemporary management of the open and TEVAR cases.

Dr Miller. We have to go back and look at those odds ratios and see which ones cross 1.0. This may look like the EVEREST-II trial (Endovascular Valve Edge-to-Repair Study): It looks great on the surface, but digging deeper reveals it is only due to differences in transfusions and ventilator time. My point is that I am concerned you are overstating your conclusions.

You mentioned on that slide that historical paraparesis/paraplegia rates after open surgical graft replacement were all $2 \%$ to $8 \%$. It should be noted that the first report on the list from Joe Coselli's group had a rate of $0.8 \%$.

Dr Desai. That was $0.8 \%$ for permanent total flaccid paralysis, and it was another $5.7 \%$ for permanent paraparesis, which has a pretty broad definition.

Dr Miller. Fair enough. It also is an adverse event defined subjectively and differently around the world. My current hobbyhorse is voicing concern that the entire thoracic field is being "dumbed down" as the TEVAR era (which we at Stanford started 19 years ago in 1992) evolves, in no small part owing to studies similar to yours in which the rule of "noninferiority" is taken as gospel. Even centers that used to know how to do open thoracic aortic surgery with reasonable results are losing those skills over time. We need to remind ourselves that the jury is still out regarding longterm durability, reintervention rates, and survival after TEVAR compared with after open graft replacement.

Dr Marc R. Moon (St Louis, Mo). Did your growth slide show that some of the aneurysms went from $4 \mathrm{~cm}$ up to 7 or $8 \mathrm{~cm}$ on follow-up?

Dr Desai. In a couple of cases, yes.

Dr Moon. What was going on there?

Dr Desai. A couple of those were converted to open. One of the lessons in our early experience with TEVAR is, if you have a proximal type I endoleak, it can evoke an unstable situation. Those aneurysms often will grow very quickly and possibly more quickly than if you had left them alone. You are mandated to reintervene either by putting a stent in and getting a proximal seal or reoperating on that patient in an open fashion. There is definitely a group of patients whose aortas will dilate out very quickly if you do not get a proximal seal.
Dr Moon. Were you replacing 4-cm aortas? What was the cutoff?

Dr Desai. Smaller sizes were seen in saccular aneurysm with rapid expansion.

Dr Pochettino. I would like to respond to Dr Miller's comment Inasmuch as I did most of the open procedures. I was actually surprised at how good the outcomes of open thoracic replacement were. That occurred despite the fact that the majority of the open operations were done via thoracotomy when the patients became unstable. The reality of the trial was that the stent grafts were not readily available, and a minimum of 6 to 8 weeks was necessary to design the endovascular repair and obtain the needed devices from the manufacturers. If the patients were stable for 6 to 8 weeks for the stent to be manufactured and shipped over, they would undergo endovascular therapy. There was an intrinsic bias of most of the patients having open surgery being relatively unstable with some of them being on the verge of aortic rupture. Despite that, the outcomes of open thoracic replacement were quite good. Nearly all of the open repair patients we would treat today with endovascular techniques.

In principle, I agree with the need for a large multi-institutional randomized study of open versus endovascular treatment of thoracic aortic aneurysm. However, with present technology, in today's world, it has become impossible to randomize between open and stent grafts. No patient would be willing to enter that study. A priori, I do not have the insight to know what is best for them, although deep down I have some opinions I could share with the patients. The opportunity to perform that large randomized study has escaped us and I do not think it is ever going to be made in today's world.

Dr Desai. If I can summarize, there certainly is a feeling by some in the literature that putting a stent graft in an aorta does not change the natural history of the aneurysmal disease, and that EVARs or TEVARs do not prolong people's lives the way that open surgery does. What we tried to show in this article was that whether you had an open operation or a TEVAR, within the limitations of the data we have discussed, your survival was similar. We do not have a true control group of patients who did not get operated on, but being operated on in an open fashion or having a TEVAR led to the same outcome, and the patient can choose which procedure he or she wants. 